\title{
Increased cardiac index attenuates septic acute kidney injury: a prospective observational study
}

\author{
Jing-chao Luo, Xiao-hua Qiu, Chun Pan, Jian-feng Xie, Tao Yu, Lin Liu, Yi Yang and Hai-bo Qiu*
}

\begin{abstract}
Background: The relationship between cardiac output and septic acute kidney injury (AKI) remains unclear. The purpose of this study was to assess the association between the cardiac index $(\mathrm{Cl})$ and the renal outcomes in patients with septic shock.

Methods: A one-year prospective cohort study was performed in the surgical and medical ICU of a teaching hospital in Nanjing, China. Twenty-nine septic shock patients who required early goal-directed fluid resuscitation were consecutively included. Pulse indicator continuous cardiac output (PiCCO) device was used to measure hemodynamic parameters before and after early goal-directed therapy (EGDT). Based on Cl changes after EGDT, patients were assign to the $\mathrm{Cl}$ increased group or the $\mathrm{Cl}$ constant group, respectively. The incidence of poor renal outcome, which was defined as AKI on admission without recovery in following three days or new onset AKI within 28 days, was recorded. We investigated whether an increased $\mathrm{Cl}$ was associated with a better renal outcome.

Results: After EGDT, there were 16 patients in the $\mathrm{Cl}$ increased group and 13 patients in the $\mathrm{Cl}$ constant group. The incidence of poor renal outcome was lower in $\mathrm{Cl}$ increased group than in the $\mathrm{Cl}$ constant group (6\% vs. 62\%; $\mathrm{P}=0.003$ ) with a relative risk of 0.10 . The logistic regression showed that the $\mathrm{Cl}$ percent change was associated with renal outcome, with an odd ratio of $0.003(\mathrm{P}=0.056)$ after adjustment of possible confounding factors. The $\mathrm{Cl}$ percent change would predict a good renal outcome (AU ROC 0.739, P = 0.012) with moderate accuracy (sensitivity $75 \%$ and specificity $89 \%$ ) when using a $10 \%$ cut-off value from Youden index. The $\mathrm{Cl}$ percent change was also positively correlated with creatinine clearance (CCr) after EGDT ( $\rho=0.548 ; P=0.002)$.
\end{abstract}

Conclusions: The increased Cl after EGDT was a protective factor for kidney in patients with septic shock. A Cl increased above $10 \%$ could be potentially used to predict development and reversibility of AKI in septic shock patients.

Trial registration: Clinicaltrials.gov:NCT01862588 (May 13, 2013).

Keywords: Septic shock, Cardiac index, Acute kidney injury

\section{Background}

As a common comorbidity among septic shock patients, acute kidney injury (AKI) prolongs hospitalization and increases mortality [1-4]. Due to compensatory renal vasoconstriction and right shifting of renal blood flow autoregulation curve, the renal hypo-perfusion becomes the leading cause of septic AKI [5,6]. Since the organ perfusion was proven to be affected by systemic hemodynamics, early goal-directed therapy (EGDT), which aims to correct circulatory failure [7], may prevent AKI.

\footnotetext{
*Correspondence: haiboq2000@163.com

Department of Critical Care Medicine, Zhong-Da Hospital, Southeast University School of Medicine, Nanjing, China
}

Kidney perfusion could be improved through increasing the mean arterial press (MAP) by implement of vasopressors or fluid infusion. Vasopressors may, however, increase the renal vascular resistance, which result in a decrease in renal blood flow [8], making it difficult to set a MAP goal to attenuate AKI $[9,10]$. In addition, achieving a high MAP goal was related to fluid overload, which may increase the risk of AKI [11,12].

Hyper-dynamic circulation was usually characterized as a high cardiac output. It was more a sign of cardiac compensation, which may lead to a better blood supply in septic shock [13,14]. An increase in cardiac output can be interpreted as an improvement in perfusion, and is associated with restoration of renal blood flow. $[14,15]$. 
Moreover, retrospective studies had shown that patients with AKI shared low cardiac index (CI) and higher central venous pressure (CVP) after resuscitation [16,17], suggesting the cardiac output may play an important role during the development of septic AKI.

This prospective cohort study was designed to investigate the relationship between $\mathrm{CI}$ and the renal outcomes, with the aim of evaluating the possibility of setting a CI goal for renal protection.

\section{Methods \\ Patients}

This non-interventional study was conducted in a 30-bed surgical and medical intensive care unit (ICU) at a teaching hospital affiliated to Southeast University in China. The protocol was approved by Jiangsu institutional Ethics Committee (Approval Number: 2013ZDSYLL075.0), and written informed consent was obtained from patients or their legally authorized representative. The trial was registered at clinicaltrial.gov (NCT01862588).

From January to December 2013, patients admitted into our ICU with documented or suspected septic shock [18] were prospectively screened. Eligibility criteria included a suspected or confirmed infection, two or more criteria for a systemic inflammatory response, and hypotension persisting after initial fluid challenge or blood lactate $>4 \mathrm{mmol} / \mathrm{L}$ [19]. Exclusion criteria were pregnancy, age $<18$ years, achieved EGDT goals already on admission, contraindication of invasive catheter, ongoing recovery from AKI, severe chronic renal failure defined by a glomerularfiltration rate $\left(\right.$ GFR) $<30 \mathrm{~m} / \mathrm{min} / 1.73 \mathrm{~m}^{2}$ [20], as well as conditions known to modify renal perfusion, such as renal-artery stenosis and severe intra-abdominal hypertension (>25 mmHg) [21].

\section{Study protocol}

(1) After admission to the ICU, blood cultures were drawn, antibiotics were administered, and fluid infusion were initiated (2) A pulse indicator continuous cardiac output $(\mathrm{PiCCO})$ device, including internal jugular vein and femoral artery catheters, was placed immediately after getting consent. The hemodynamic parameters were collected through the thermo-dilution method. (3) Due to the observational nature of the study, the physician implemented the EGDT according to the guidelines [19]. (4) After achieving the EGDT goals (CVP 8 to $12 \mathrm{mmHg}$, MAP $\geq 65 \mathrm{mmHg}$, urine output (UO) $\geq 0.5 \mathrm{ml} / \mathrm{kg} / \mathrm{hr}$ and central venous oxygen saturation $\left(\mathrm{ScvO}_{2}\right) \geq 70 \%$ [7]) and allowing patient to stabilize for 30 minutes, the hemodynamic parameters were recorded again. (5) Data collected from patients who achieved EGDT goals within 12 hrs were analyzed, and divided into two groups based on CI changes. Patients were followed up for 28 days, or until death, monitoring the development of AKI.

\section{Data collection}

The basic characteristics such as age, mechanical ventilation, acute physiology and chronic health evaluation score II (APACHE score II), and infection site were collected. Hemodynamic parameters, including CVP, MAP, $\mathrm{ScvO}_{2}, \mathrm{CI}$, stroke volume index (SVI), systemic vascular resistance index (SVRI), global end-diastolic volume index (GEDI), global ejection fraction (GEF), cardiac function index (CFI), and arterial lactate acid (Lac), were recorded. Additionally, 2-hr urine output, serum creatinine $(\mathrm{Cr})$, serum urea nitrogen (BUN), serum neutrophil gelatinaseassociated lipocalin (NGAL, ELISA kit, Uscn Life Science Inc, Wuhan, PRC), urine creatinine, creatinine clearance $(\mathrm{CCr})$ and fractional excretion of sodium (FeNa) were also recorded before and after EGDT. The height and weight

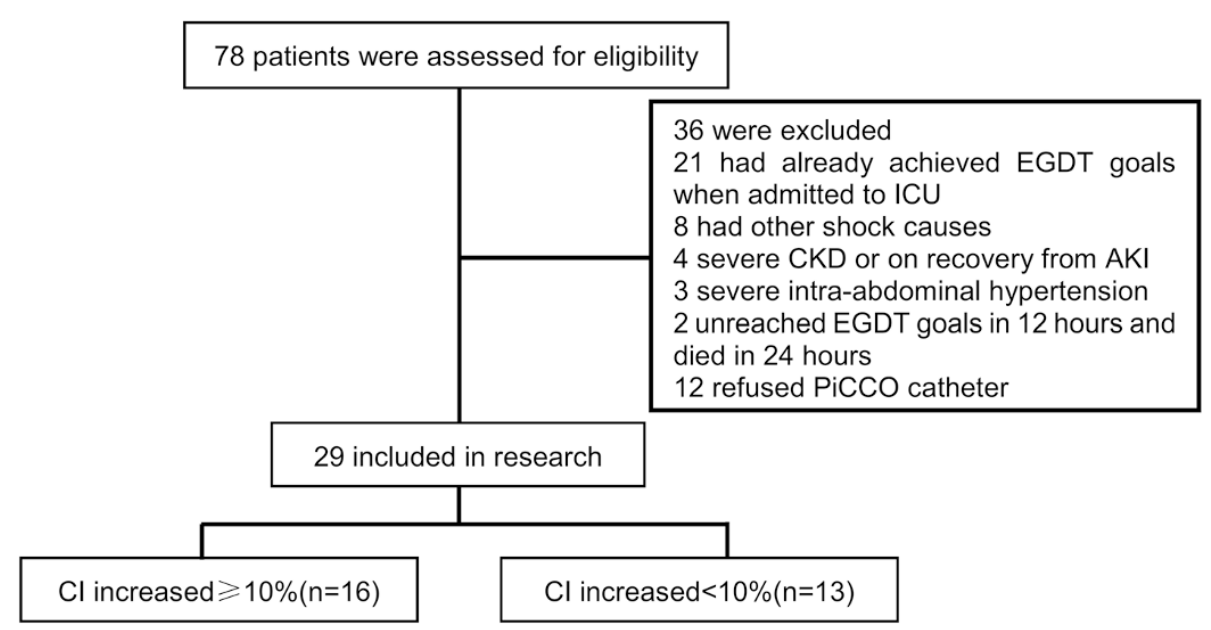

Figure 1 Flowchart of patients included in the study. EGDT, early goal-directed therapy; CKD, chronic kidney disease; PiCCO, Pulse indicator continuous cardiac output; $\mathrm{Cl}$, cardiac index. 
were based on recent measurements obtained from patients or their next of kin.

\section{Outcome measures}

The primary end point was poor renal outcome at day 28. For each patient, the incidence of AKI was evaluated according to the Kidney Disease: Improving Global Outcomes (KDIGO) criteria [22], which proposed criteria for three stages of increasing severity. The basal serum creatinine level was set as the lowest value in the 3 months preceding inclusion. If no serum creatinine were available, the lowest value during ICU stay (during renal recovery) or average level of same age bracket among Chinese population [23] was used to assess underlying renal function. Poor renal outcome was defined as persistent AKI (KDIGO stage $2-3$ on admission and did not recover to stage $0-1$ in 3 days) or development of new AKI (KDIGO stage $2-3)[16,24]$. The secondary end point was mortality at day 28 .

\section{Statistics}

Data are presented as median and interquartile range or number and percentage, as appropriate. Categorical variables were compared using the Fisher's exact test, continuous variables were compared using several tests: for pre and post measurements, the nonparametric Wilcoxon test was used; for pairwise comparisons, the Mann-Whitney test; for comparisons across the three group, the Kruskalwallis test. Receiver operating characteristic (ROC) curves and Youden index were used to choose the appropriate cutoff points. The relationships between variables were evaluated through the use of Spearman correlation. Logistic regression analysis, with or without adjustment for potential confounding factors, was used to confirm the correlation. A significance level 0.05 was chosen for all tests in SPSS 17.0 software.

\section{Results}

\section{Patients' characteristics}

Twenty-nine septic shock patients were included after screening and application of selection criteria (Figure 1). Considering the systemic error of thermo-dilution method, a cut-off value of $10 \%$ for CI increase [25] was used. In total, we observed 16 patients with $\mathrm{CI}$ increase (CI increased group) and the rest 13 patients were divided in CI constant group. Factors such as age, hypertension or diabetes mellitus, APACHE score II, the use of vasopressors or resuscitation fluid, 28-day mortality, etc. made no significant difference between both groups (Table 1). Yet, the levels of CI, SVI, GEF and CFI after EGDT were higher in the CI constant group than those in the CI increased group (Table 2).
Table 1 Patients' characteristics

\begin{tabular}{|c|c|c|c|}
\hline & $\begin{array}{l}\mathrm{Cl} \text { constant } \\
\text { group }(n=13)\end{array}$ & $\begin{array}{l}\mathrm{Cl} \text { increased } \\
\text { group }(n=16)\end{array}$ & $P$ value \\
\hline Age (years) & 78(69-86) & $75(65-83)$ & 0.29 \\
\hline Males n (\%) & $7(54)$ & $8(50)$ & 1.00 \\
\hline Hypertension n (\%) & $9(69)$ & 10(63) & 1.00 \\
\hline Diabetes mellitus n (\%) & $5(38)$ & $4(25)$ & 0.69 \\
\hline \multicolumn{4}{|l|}{ Source of infection } \\
\hline Lungs n (\%) & $6(46)$ & $10(63)$ & 0.47 \\
\hline Abdomen n (\%) & $7(54)$ & $4(25)$ & 0.14 \\
\hline Soft tissue $n(\%)$ & $0(0)$ & $1(6)$ & 1.00 \\
\hline Other $\mathrm{n}(\%)$ & $0(0)$ & $1(6)$ & 1.00 \\
\hline APACHE score II & $24(24-30)$ & 23(19-27) & 0.13 \\
\hline SOFA score & $11(10-12)$ & $11(8-12)$ & 0.19 \\
\hline $\begin{array}{l}\text { Mechanical ventilation } \\
\mathrm{n}(\%)\end{array}$ & $10(77)$ & 13(81) & 0.70 \\
\hline $\begin{array}{l}\text { Norepinephrine } \\
\text { (ug/kg/min) }\end{array}$ & $0.3(0.1-0.4)$ & $0.2(0.2-0.4)$ & 0.36 \\
\hline \multicolumn{4}{|l|}{ Fluid Therapy } \\
\hline $\begin{array}{l}\text { Hydroxyethyl starch } \\
\text { n (\%) }\end{array}$ & $8(62)$ & $7(44)$ & 0.46 \\
\hline Colloid fluid n (\%) & $11(85)$ & $13(81)$ & 1.00 \\
\hline $\begin{array}{l}\text { Hydroxyethyl starch } \\
\text { amount (ml/kg) }\end{array}$ & 11.7(7.1-18.6) & $7.9(7.1-10.0)$ & 0.20 \\
\hline $\begin{array}{l}\text { Colloid fluid amount } \\
(\mathrm{ml} / \mathrm{kg})\end{array}$ & 13.8(7.1-20.0) & $8.2(5.0-10.6)$ & 0.20 \\
\hline $\begin{array}{l}\text { Crystalloid fluid } \\
\text { amount (ml/kg) }\end{array}$ & 26.8(15.7-34.7) & 28.3(18.9-42.8) & 0.51 \\
\hline $\begin{array}{l}\text { Resuscitation fluid } \\
\text { amount }(\mathrm{ml} / \mathrm{kg})\end{array}$ & $35.8(27.6-53.6)$ & $36.1(25.8-52.4)$ & 0.86 \\
\hline EGDT period (hour) & $6.0(6.0-7.0)$ & $6.0(5.0-6.0)$ & 0.27 \\
\hline $\begin{array}{l}\text { Poor renal outcome } \\
\text { n (\%) }\end{array}$ & $8(62)$ & $1(6)$ & 0.003 \\
\hline $\begin{array}{l}\text { AKI 2-3on admission } \\
n(\%)\end{array}$ & $6(46)$ & $4(25)$ & 0.27 \\
\hline Persistent AKI n (\%) & $4(31)$ & $1(6)$ & 0.14 \\
\hline $\begin{array}{l}\text { AKI 0-10n admission } \\
\mathrm{n}(\%)\end{array}$ & $7(54)$ & $12(75)$ & 0.27 \\
\hline New AKI n (\%) & $2(15)$ & $0(0)$ & 0.19 \\
\hline $\begin{array}{l}\text { Use of renal-replacement } \\
\text { therapy } n(\%)\end{array}$ & $6(46)$ & $3(19)$ & 0.23 \\
\hline Days in ICU (days) & $8(6-14)$ & $8(7-19)$ & 0.98 \\
\hline 28-day mortality n (\%) & $6(46)$ & $5(31)$ & 0.47 \\
\hline
\end{tabular}

$\mathrm{Cl}$, cardiac index; APACHE, Acute physiology, age, chronic health evaluation; SOFA, sequential organ failure assessment. The data in the table are expressed as median (interquartile range) or number (\%).

\section{Relationship between $\mathrm{Cl}$ changes and renal function during resuscitation}

After EGDT, the urine output and $\mathrm{CCr}$ increased in $\mathrm{CI}$ increased group while decreased in CI constant group (Table 3). The median $\mathrm{CCr}$ after resuscitation was higher in CI increased group than in CI constant group (Table 3). 
Table 2 Hemodynamic parameters before and after EGDT

\begin{tabular}{|c|c|c|c|c|}
\hline & & $\mathrm{Cl}$ constant group $(n=13)$ & $\mathrm{Cl}$ increased group $(n=16)$ & $P$ value \\
\hline \multirow[t]{3}{*}{ HR (beats/min) } & Before EGDT & 113(90-134) & $117(87-130)$ & 0.69 \\
\hline & After EGDT & $91(73-114)$ & $95(78-107)$ & 0.76 \\
\hline & $P$ value & 0.002 & 0.013 & \\
\hline \multirow[t]{3}{*}{ MAP $(\mathrm{mmHg})$} & Before EGDT & $65(58-73)$ & $64(55-67)$ & 0.60 \\
\hline & After EGDT & 87(69-98) & $86(76-93)$ & 0.96 \\
\hline & $P$ value & 0.002 & $<0.001$ & \\
\hline \multirow[t]{3}{*}{ CVP $(\mathrm{mmHg})$} & Before EGDT & $10(5-12)$ & $6(4-11)$ & 0.56 \\
\hline & After EGDT & $10(8-15)$ & $11(8-15)$ & 0.89 \\
\hline & $P$ value & 0.045 & 0.004 & \\
\hline \multirow[t]{3}{*}{$\mathrm{Cl}\left(\mathrm{L} / \mathrm{min} / \mathrm{m}^{2}\right)$} & Before EGDT & $3.2(2.7-4.3)$ & $2.6(2.2-3.2)$ & 0.06 \\
\hline & After EGDT & $3.0(2.6-4.0)$ & $3.8(3.1-5.2)$ & 0.028 \\
\hline & $P$ value & 0.022 & $<0.001$ & \\
\hline \multirow[t]{3}{*}{$\mathrm{SVI}\left(\mathrm{ml} / \mathrm{m}^{2}\right)$} & Before EGDT & $34(28-37)$ & $29(23-36)$ & 0.14 \\
\hline & After EGDT & $36(32-38)$ & $43(40-48)$ & 0.003 \\
\hline & $P$ value & 0.11 & $<0.001$ & \\
\hline \multirow[t]{3}{*}{ SVRI (dyn.s. $\left.\mathrm{m}^{2} / \mathrm{cm}^{5}\right)$} & Before EGDT & 1478(1231-2076) & $1722(1497-2373)$ & 0.34 \\
\hline & After EGDT & $1652(1273-2391)$ & 1545(1185-1881) & 0.43 \\
\hline & $P$ value & 0.06 & 0.163 & \\
\hline \multirow[t]{3}{*}{ GEDI $\left(\mathrm{ml} / \mathrm{m}^{2}\right)$} & Before EGDT & 793(670-936) & $651(634-771)$ & 0.035 \\
\hline & After EGDT & 878(673-1056) & $767(697-886)$ & 0.50 \\
\hline & $P$ value & 0.17 & $<0.001$ & \\
\hline \multirow[t]{3}{*}{ GEF (\%) } & Before EGDT & 15(13-20) & $17(16-22)$ & 0.19 \\
\hline & After EGDT & $16(13-20)$ & $23(20-24)$ & 0.012 \\
\hline & $P$ value & 0.36 & 0.013 & \\
\hline \multirow[t]{3}{*}{ CFI (L/min) } & Before EGDT & $4.0(3.2-5.3)$ & $4.2(3.7-4.9)$ & 0.96 \\
\hline & After EGDT & $3.8(2.9-4.5)$ & $5.0(4.4-5.9)$ & 0.003 \\
\hline & $P$ value & 0.008 & 0.003 & \\
\hline \multirow[t]{3}{*}{$\mathrm{ScvO}_{2}(\%)$} & Before EGDT & $80(73-85)$ & $79(76-81)$ & 0.66 \\
\hline & After EGDT & $80(75-83)$ & $84(81-84)$ & 0.026 \\
\hline & $P$ value & 0.81 & 0.005 & \\
\hline \multirow[t]{3}{*}{ Lac (mmol/L) } & Before EGDT & $3.2(1.5-5.1)$ & $2.4(1.3-3.3)$ & 0.44 \\
\hline & After EGDT & $1.7(1.2-2.8)$ & $1.3(0.9-1.7)$ & 0.25 \\
\hline & $P$ value & 0.039 & 0.03 & \\
\hline
\end{tabular}

MAP, mean arterial pressure; CVP, central venous pressure; HR, heart rate; Cl, cardiac index; SVI, stroke volume index; SVRI, systemic vascular resistance index; GEDI, global end-diastolic volume index; GEF, global ejection fraction; ScvO2, central venous oxygen saturation; Lac, arterial lactate acid. The data in the table are expressed as median (interquartile range) or number (\%).

A linear regression model shown that the CI percent change associated with $\mathrm{CCr}$ percent change $(\rho=0.524$; $P=0.004)$ and $C C r$ level after resuscitation $(\rho=0.548$; $\mathrm{P}=0.002$ ) (Figure 2).

\section{Relationship between $\mathrm{Cl}$ changes and renal outcomes}

The incidence of poor renal outcomes was lower in CI increased group than in the CI constant group (6\% vs. $62 \% ; \mathrm{P}=0.003)$ with a relative risk of 0.10 . The singlefactor analysis also shown that the $\mathrm{CI}$ percent change
(33\% [2\% to $59 \%]$ vs. 0 [ $-10 \%$ to $8 \%] ; \mathrm{P}=0.043$ ) differed between patients with different renal outcomes. After adjustment of possible confounding factors (GEDI percent change: $\mathrm{OR}=1.625, \mathrm{P}=0.910$; APACHE score II: $\mathrm{OR}=$ $1.067, \mathrm{P}=0.598$; total resuscitation fluid amount: $\mathrm{OR}=1.038$, $\mathrm{P}=0.365$; basal serum $\mathrm{Cr}$ level: $\mathrm{OR}=0.987, \mathrm{P}=0.229$ ), the OR between $\mathrm{CI}$ percent change and poor renal outcome was $0.003(\mathrm{P}=0.056)$. The $\mathrm{CI}$ percent change had a moderate predictive accuracy of AKI recovery with an area under the ROC curve of $0.739(P=0.012$ ) (Figure 3$)$. A cutoff 
Table 3 Renal function parameters before and after EGDT

\begin{tabular}{|c|c|c|c|c|}
\hline & & $\mathrm{Cl}$ constant group $(n=13)$ & $\mathrm{Cl}$ increased group $(n=16)$ & $P$ value \\
\hline \multirow[t]{3}{*}{ Serum Cr(umol/L) } & Before EGDT & $68(49-261)$ & $83(56-133)$ & 0.74 \\
\hline & After EGDT & $83(55-215)$ & $76(63-127)$ & 0.86 \\
\hline & $P$ value & 1.0 & 0.98 & \\
\hline \multirow[t]{3}{*}{ Serum Bun(mmol/L) } & Before EGDT & 8.4(4.9-14.4) & $7.8(5.7-10.0)$ & 0.61 \\
\hline & After EGDT & $8.5(4.5-14.8)$ & $7.9(4.7-9.0)$ & 0.65 \\
\hline & $P$ value & 0.27 & 0.27 & \\
\hline \multirow[t]{3}{*}{ Serum NGAL(ng/ml) } & Before EGDT & $140(70-375)$ & $74(28-148)$ & 0.11 \\
\hline & After EGDT & $169(60-254)$ & $125(60-179)$ & 0.55 \\
\hline & $P$ value & 0.68 & 0.048 & \\
\hline \multirow[t]{3}{*}{ Urinary $\operatorname{Cr}($ umol/L) } & Before EGDT & 4010 (2395-9143) & 7894(3424-9910) & 0.24 \\
\hline & After EGDT & $2766(2100-8817)$ & $3642(2174-7375)$ & 0.69 \\
\hline & $P$ value & 0.60 & 0.004 & \\
\hline \multirow[t]{3}{*}{ Urine output(ml/h) } & Before EGDT & $85(40-128)$ & 73(23-119) & 0.35 \\
\hline & After EGDT & $67(43-128)$ & $98(70-150)$ & 0.11 \\
\hline & $P$ value & 0.31 & 0.013 & \\
\hline \multirow[t]{3}{*}{$\mathrm{Ccr}(\mathrm{ml} / \mathrm{min})$} & Before EGDT & $85(17-129)$ & $59(45-101)$ & 0.69 \\
\hline & After EGDT & $53(22-93)$ & $82(52-126)$ & 0.08 \\
\hline & $P$ value & 0.034 & 0.12 & \\
\hline \multirow[t]{3}{*}{$\mathrm{FeNa}(\%)$} & Before EGDT & $0.6(0.1-12.3)$ & $0.7(0.3-1.5)$ & 0.64 \\
\hline & After EGDT & $1.0(0.1-8.9)$ & $1.0(0.5-1.8)$ & 0.83 \\
\hline & $P$ value & 0.53 & 0.41 & \\
\hline
\end{tabular}

$\mathrm{Cr}$, creatinine; Bun, urea nitrogen; NGAL, neutrophil gelatinase-associated lipocalin; Ccr, creatinine clearance; FeNa, fractional excretion of sodium. The data in the table are expressed as median (interquartile range) or number (\%).

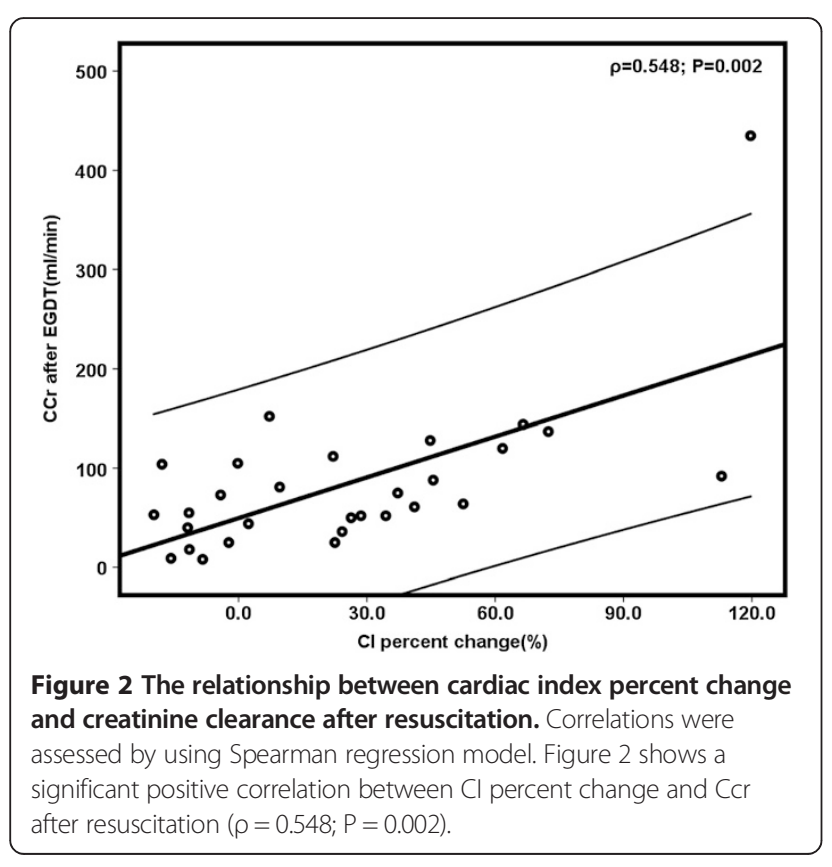

value of $10 \%$ increased CI determined by the Youden index would reach a sensitivity of $75 \%$ and a specificity of $89 \%$.

\section{Relationship between $\mathrm{Cl}$ after EGDT and renal outcome}

Based on a retrospective study [17] which reported that a much high cardiac output was associated with worse outcome, we divided patients into three groups according to the CI after EGDT. The incidence of poor renal outcomes was $44 \%(4 / 9)$ in patients with a CI $<3.0 \mathrm{~L} / \mathrm{min} / \mathrm{m}^{2}$, $10 \%(1 / 10)$ in patients with a CI $3.0-4.0 \mathrm{~L} / \mathrm{min} / \mathrm{m}^{2}$ and $40 \%(4 / 10)$ in patients with a $\mathrm{CI}>4.0 \mathrm{~L} / \mathrm{min} / \mathrm{m}^{2}$, however, no statistical differences were observed $(P=0.20)($ Table 4$)$. The CI after EGDT was not sufficient to predict renal outcome with an area under the ROC curve of 0.556 $(\mathrm{P}=0.115)$ (Figure 3).

\section{Discussion}

The present study demonstrated that the increased CI during EGDT was a protective factor of AKI. The increased CI was not only associated with better renal function, but also associated with better renal outcome.

Renal hypo-perfusion was one of the main causes of septic AKI [6], thus restoration of renal blood flow may benefit kidney. Hyper-dynamic circulation, characterized 


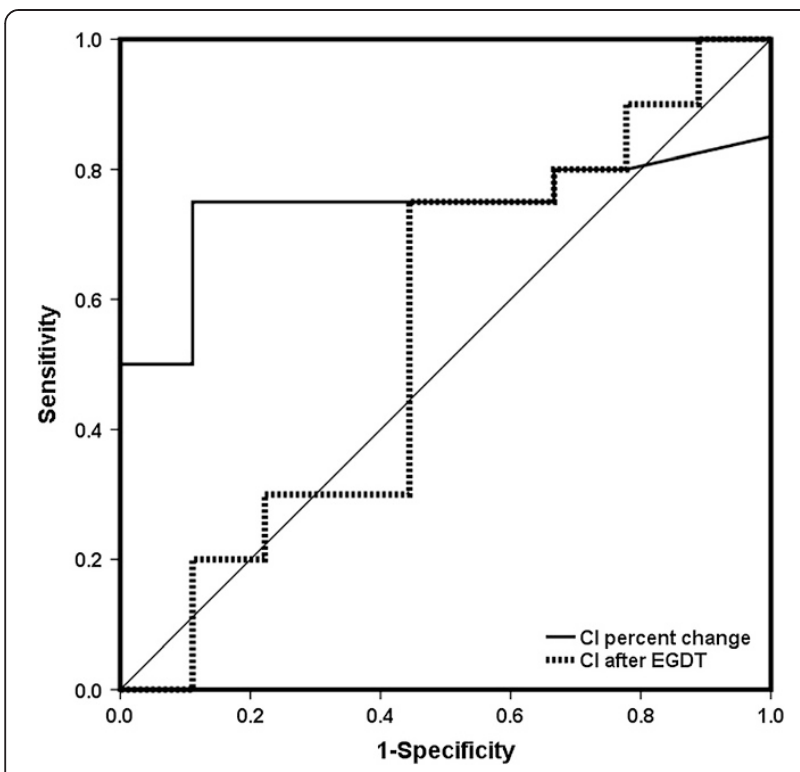

Figure 3 Receiver-operating characteristic (ROC) curve depicting the cardiac index $(\mathrm{Cl})$ percent change (\%) or $\mathrm{Cl}$ after early goaldirected therapy (EGDT) to predict good renal outcome. The area under ROC curves were $0.739(\mathrm{P}=0.012)$ of $\mathrm{Cl}$ percent change to predict non-poor renal outcome. A cutoff value of 10\% determined by Youden index would provide a sensitivity of $89 \%$ and a specificity of $75 \%$. The area under ROC curves were $0.556(\mathrm{P}=0.115)$ of $\mathrm{Cl}$ after EGDT to predict non-poor renal outcome. A cutoff value of $3.0 \mathrm{~L} / \mathrm{min} / \mathrm{m}^{2}$ determined by Youden index would provide a sensitivity of $56 \%$ and a specificity of $75 \%$.

by high cardiac output, was common in septic shock and would lead to better perfusion of organs, including heart, brain, liver, guts, and especially the kidney [13-15]. In animal sepsis studies conducted by Langenberg, et al., increased renal blood flow along with cardiac output was also observed $[15,26,27]$. In this study, despite lacking of direct renal perfusion monitoring, we observed that the $\mathrm{CCr}$ was increasing together with $\mathrm{CI}$ changes during EGDT, suggesting the kidney may benefit from improvement of global circulation. Furthermore, the renal outcome in CI increased group was better than CI constant group, and a regression analysis has confirmed increased CI was a protective factor for kidney after adjusting any possible confounding factors.

The survival sepsis campaign guidelines well promoted the early initiation of fluid and vasopressors in patients with septic shock. Most patients had already received different doses of fluid before admitted to ICU (in the emergency department or even in the ambulance) and 13 patients in our study complete 3 of the 4 EGDT goals when admitted. However, the EGDT goals, as the fundamental targets, were not the endpoint of early resuscitation $[7,28,29]$. In this study, the great improvement of MAP, HR, Lac during the early resuscitation were observed, suggesting a potential space for progression, which enabled us to further investigate the benefits of increased CI.

Various reasons might contribute to the constant CI in part of patients. Physiologically, the cardiac output is determined by the volume status and fluid responsiveness. After EGDT, though receiving same dose of fluid, the volume status parameters (CVP or GEDI) increased apparently in CI increased group, suggesting a better fluid responsiveness with these patients. The higher CVP and GEDI in the CI constant group before EGDT indicated a sign of more sufficient blood volume, and further infusion of fluid would not transfer to more cardiac output (Starling principle). Besides, the reduction of myocardial contractility usually results from sepsis, which was induced by myocardial depression [30]. It may also play a role in the absence of fluid responsiveness. We noticed that, concerning the similar volume status (before EGDT in

Table 4 Relation between hemodynamic parameters and outcomes

\begin{tabular}{|c|c|c|c|c|}
\hline & $\mathrm{Cl}<3.0 \mathrm{~L} / \mathrm{min} / \mathrm{m} 2(\mathrm{n}=9)$ & $\mathrm{Cl} 3.0-4.0 \mathrm{~L} / \mathrm{min} / \mathrm{m} 2(\mathrm{n}=10)$ & $\mathrm{Cl}>4.0 \mathrm{~L} / \mathrm{min} / \mathrm{m} 2(\mathrm{n}=10)$ & $P$ value \\
\hline Age (years) & $81(76-86)$ & $75(63-84)$ & $74(61-86)$ & 0.39 \\
\hline APACHE score II & $24(20-25)$ & $24(20-31)$ & $25(20-30)$ & 0.70 \\
\hline CVP after EGDT(mmHg) & $8(7-11)$ & $13(10-15)$ & 11(9-16) & 0.03 \\
\hline GEDI after EGDT $\left(\mathrm{ml} / \mathrm{m}^{2}\right)$ & $722(613-970)$ & $785(696-950)$ & $881(766-952)$ & 0.42 \\
\hline MAP after EGDT(mmHg) & $95(85-102)$ & $85(76-93)$ & $77(71-90)$ & 0.06 \\
\hline $\mathrm{ScvO}_{2}$ after EGDT(\%) & $82(74-85)$ & $81(80-83)$ & $84(82-87)$ & 0.17 \\
\hline Norepinephrine (ug/kg/min) & $0.1(0-0.3)$ & $0.3(0.1-0.7)$ & $0.2(0.1-0.4)$ & 0.54 \\
\hline Hydroxyethyl starch n (\%) & $5(56)$ & $6(60)$ & $4(40)$ & 0.98 \\
\hline Hydroxyethyl starch amount $(\mathrm{ml} / \mathrm{kg})$ & 10.0(7.1-12.2) & $9.0(6.3-12.5)$ & 10.6(7.3-18.9) & 0.77 \\
\hline Resuscitation fluid amount $(\mathrm{ml} / \mathrm{kg})$ & $31.7(19.4-37.9)$ & $33.9(25.2-55.9)$ & $44.5(32.3-62.9)$ & 0.08 \\
\hline Poor renal outcome n (\%) & $4(44)$ & $1(10)$ & $4(40)$ & 0.20 \\
\hline 28-day mortality n (\%) & $4(44)$ & $3(30)$ & $4(40)$ & 0.80 \\
\hline
\end{tabular}

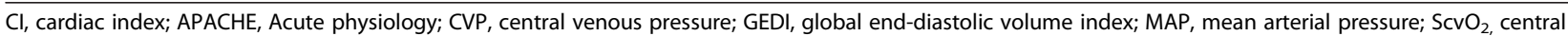
venous oxygen saturation; The data in the table are expressed as median (interquartile range) or number (\%). 
the $\mathrm{CI}$-increased group vs. after EGDT in the $\mathrm{CI}$ increased group), the SVI, GEF and CFI were lower in the $\mathrm{CI}$-increased group, and they may show a significant difference in myocardial contractility between groups (Table 2).

Though increased cardiac output may attenuate poor renal outcome, we failed to define a CI goal which has the minimal risk of AKI. Based on a previous research [17], either a much lower or higher cardiac output may be harmful. When divided patients into three groups, the incidence of poor renal outcome distributed in valley form and a CI between 3.0-4.0 L/min $/ \mathrm{m}^{2}$ seems less likely to develop AKI. There may be two hypotheses for the phenomenon: First, a higher cardiac output not only increases oxygen deliver for the kidney, but also brings harmful inflammatory factors or oxygen free radicals [31]; Second, it is likely that a higher cardiac index is a sign of worse sepsis with poor oxygen extraction and higher compensated perfusion [32], and therefore these patients were more prone to develop AKI. Though it was necessary to evaluate an upper limit of cardiac output goal, however, the area under ROC curve was not good enough to determine a CI goal based on our present data.

Renal protection needs an accurate prediction on development and progression of AKI. However, evaluation for the AKI risk remained uncertainty. Although the AKI biomarker and renal Doppler were two promising methods for AKI evaluation [33,34], they were either too complex or expensive to be widely accepted by clinical physicians and technicians. Our study had demonstrated that the CI changes were correlated with renal outcomes, which a $10 \%$ $\mathrm{CI}$ increased could be used as an indicator. Besides, the CI could be easily monitored at bedside, which made itself more applicable in critical care departments.

\section{Limitations}

Our study had several limitations. First, being completely blind to the patients' clinical conditions seemed almost impossible. So a doctor who was unaware of our research details designed the fluid resuscitation plans. Moreover, the sample size was not considerable quantity even though we have adequate power, the study needs to be repeated in a larger, multicenter cohort. Only those patients who had received PiCCO monitor were included in current research, which might introduce bias. Additionally, patients who had received treatment in emergency department and those who had already achieved EGDT goals during ICU admission were excluded, therefore potentially the sample size was reduced. Finally, some patients received infusion of hydroxyethyl starch during resuscitation, which may affect renal function as well. However, there were no significant differences in portions or doses of hydroxyethyl starch between groups.

\section{Conclusion}

In this study, we found that increased CI during EGDT was associated with a better renal outcome and could be potentially used to predict the development or progression of AKI. Targeting a 10\% CI increment for reducing the risk of AKI should be considered in this setting.

\section{Abbreviations}

AKI: Acute kidney injury; APACHE score II: Acute physiology and chronic health evaluation score II; BUN: Serum urea nitrogen; CCr: Creatinine clearance; CFI: Cardiac function index; Cl: Cardiac index; CVP: Central venous pressure; EGDT: Early goal directed therapy; FeNa: Fractional excretion of sodium; GEDI: Global end-diastolic volume index; GEF: Global ejection fraction; GFR: Glomerular-filtration rate; HR: Heart rate; MAP: Mean arterial pressure; NGAL: Neutrophil gelatinase-associated lipocalin; PiCCO: Pulse indicator continuous cardiac output; ScvO2: Central venous oxygen saturation; SVI: Stroke volume index; SVRI: Systemic vascular resistance index; UO: Urine output.

\section{Competing interests}

The authors declare that they have no competing interests.

\section{Authors' contributions}

$\mathrm{JCL}, \mathrm{XHQ}$ and $\mathrm{HBQ}$ conceived and designed the study, contributed to the analysis and interpretation of data as well as drafting the manuscript, and gave their final approval of the version to be published. CP, JFX, TY, LL and YY contributed to the acquisition, analysis and interpretation of data and gave their final approval of the version to be published. All authors read and approved the final manuscript.

\section{Acknowledgements}

The authors thank Mr Hui Jin of Public Health College of Southeast University for his statistical assistance.

Received: 14 August 2014 Accepted: 20 February 2015

Published online: 01 March 2015

\section{References}

1. Myburgh JA, Finfer S, Bellomo R, Billot L, Cass A, Gattas D, et al. Hydroxyethyl starch or saline for fluid resuscitation in intensive care. N Engl J Med. 2012;367(20):1901-11.

2. Perner A, Haase N, Guttormsen AB, Tenhunen J, Klemenzson G, Aneman A, et al. Hydroxyethyl starch 130/0.42 versus Ringer's acetate in severe sepsis. N Engl J Med. 2012;367(2):124-34.

3. Kim WY, Huh JW, Lim CM, Koh Y, Hong SB. A comparison of acute kidney injury classifications in patients with severe sepsis and septic shock. Am J Med Sci. 2012;344(5):350-6.

4. Uchino S, Kellum JA, Bellomo R, Doig GS, Morimatsu H, Morgera S, et al. Beginning, ending supportive therapy for the kidney I: acute renal failure in critically ill patients: a multinational, multicenter study. JAMA. 2005;294(7):813-8.

5. Abuelo JG. Normotensive ischemic acute renal failure. N Engl J Med. 2007;357(8):797-805

6. Lipcsey M, Bellomo R. Septic acute kidney injury: hemodynamic syndrome, inflammatory disorder, or both? Crit Care. 2011;15(6):1008.

7. Rivers E, Nguyen B, Havstad S, Ressler J, Muzzin A, Knoblich B, et al. Early goal-directed therapy in the treatment of severe sepsis and septic shock. N Engl J Med. 2001;345(19):1368-77.

8. Deruddre S, Cheisson G, Mazoit JX, Vicaut E, Benhamou D, Duranteau J. Renal arterial resistance in septic shock: effects of increasing mean arterial pressure with norepinephrine on the renal resistive index assessed with Doppler ultrasonography. Intensive Care Med. 2007;33(9):1557-62.

9. Asfar P, Meziani F, Hamel JF, Grelon F, Megarbane B, Anguel N, et al. High versus low blood-pressure target in patients with septic shock. N Engl J Med. 2014;370(17):1583-93

10. Badin J, Boulain T, Ehrmann S, Skarzynski M, Bretagnol A, Buret J, et al. Relation between mean arterial pressure and renal function in the early phase of shock: a prospective, explorative cohort study. Crit Care. 2011;15(3):R135.

11. Prowle JR, Chua HR, Bagshaw SM, Bellomo R. Volume of fluid resuscitation and the incidence of acute kidney injury - a systematic review. Crit Care. 2012;16(4):230. 
12. Correa TD, Vuda M, Takala J, Djafarzadeh S, Silva E, Jakob SM. Increasing mean arterial blood pressure in sepsis: effects on fluid balance, vasopressor load and renal function. Crit Care. 2013;17(1):R21.

13. Albuszies $G$, Radermacher P, Vogt J, Wachter U, Weber S, Schoaff M, et al. Effect of increased cardiac output on hepatic and intestinal microcirculatory blood flow, oxygenation, and metabolism in hyperdynamic murine septic shock. Crit Care Med. 2005;33(10):2332-8.

14. Di Giantomasso D, May CN, Bellomo R. Norepinephrine and vital organ blood flow during experimental hyperdynamic sepsis. Intensive Care Med. 2003;29(10):1774-81.

15. Langenberg C, Wan L, Egi M, May CN, Bellomo R. Renal blood flow in experimental septic acute renal failure. Kidney Int. 2006;69(11):1996-2002.

16. Legrand M, Dupuis C, Simon C, Gayat E, Mateo J, Lukaszewicz AC, et al. Association between systemic hemodynamics and septic acute kidney injury in critically ill patients: a retrospective observational study. Crit Care. 2013;17(6):R278.

17. Yang RL, Wang XT, Liu DW. The hemodynamic characteristic and prognosis significance of acute kidney injury caused by septic shock. Zhonghua Nei Ke Za Zhi. 2009:48(9):715-9.

18. Levy MM, Fink MP, Marshall JC, Abraham E, Angus D, Cook D, et al. 2001 SCCM/ESICM/ACCP/ATS/SIS International Sepsis Definitions Conference. Crit Care Med. 2003;31(4):1250-6

19. Dellinger RP, Levy MM, Rhodes A, Annane D, Gerlach H, Opal SM, et al. Surviving sepsis campaign: international guidelines for management of severe sepsis and septic shock: 2012. Crit Care Med. 2013;41(2):580-637.

20. Levey AS, Eckardt KU, Tsukamoto Y, Levin A, Coresh J, Rossert J, et al. Definition and classification of chronic kidney disease: a position statement from Kidney Disease: Improving Global Outcomes (KDIGO). Kidney Int. 2005;67(6):2089-100.

21. Kirkpatrick AW, Roberts DJ, De Waele J, Jaeschke R, Malbrain ML, De Keulenaer $B$, et al. Intra-abdominal hypertension and the abdominal compartment syndrome: updated consensus definitions and clinical practice guidelines from the World Society of the Abdominal Compartment Syndrome. Intensive Care Med. 2013;39(7):1190-206.

22. Group. KDIGOKAKIW. KDIGO Clinical Practice Guideline for Acute Kidney Injury. Kidney inter. 2012;2:1-138.

23. Kong X, Ma Y, Chen J, Luo Q, Yu X, Li Y, et al. Evaluation of the Chronic Kidney Disease Epidemiology Collaboration equation for estimating glomerular filtration rate in the Chinese population. Nephrol Dial Transplant. 2013;28(3):641-51.

24. Schnell D, Deruddre S, Harrois A, Pottecher J, Cosson C, Adoui N, et al. Renal resistive index better predicts the occurrence of acute kidney injury than cystatin C. Shock. 2012;38(6):592-7.

25. Diebel LN, Wilson RF, Tagett MG, Kline RA. End-diastolic volume, A better indicator of preload in the critically ill. Arch Surg. 1992;127(7):817-21. discussion 821-812.

26. Langenberg C, Bellomo R, May C, Wan L, Egi M, Morgera S. Renal blood flow in sepsis. Crit Care. 2005;9(4):R363-74.

27. Langenberg C, Wan L, Egi M, May CN, Bellomo R. Renal blood flow and function during recovery from experimental septic acute kidney injury. Intensive Care Med. 2007;33(9):1614-8.

28. Investigators A, Group ACT, Peake SL, Delaney A, Bailey M, Bellomo R, et al. Goal-directed resuscitation for patients with early septic shock. N Engl J Med. 2014;371(16):1496-506.

29. Pro Cl, Yealy DM, Kellum JA, Huang DT, Barnato AE, Weissfeld LA, et al. A randomized trial of protocol-based care for early septic shock. N Engl J Med. 2014;370(18):1683-93.

30. Zaky A, Deem S, Bendjelid K, Treggiari MM. Characterization of cardiac dysfunction in sepsis: an ongoing challenge. Shock. 2014:41(1):12-24.

31. Benes J, Chvojka J, Sykora R, Radej J, Krouzecky A, Novak I, et al. Searching for mechanisms that matter in early septic acute kidney injury: an experimental study. Crit Care. 2011;15(5):R256

32. Parrillo JE, Parker MM, Natanson C, Suffredini AF, Danner RL, Cunnion RE, et al. Septic shock in humans. Advances in the understanding of pathogenesis, cardiovascular dysfunction, and therapy. Ann Intern Med. 1990;113(3):227-42.

33. Schnell D, Darmon M. Renal Doppler to assess renal perfusion in the critically ill: a reappraisal. Intensive Care Med. 2012;38(11):1751-60.

34. Ostermann M, Philips BJ, Forni LG. Clinical review: biomarkers of acute kidney injury: where are we now? Crit Care. 2012;16(5):233.

\section{Submit your next manuscript to BioMed Central and take full advantage of:}

- Convenient online submission

- Thorough peer review

- No space constraints or color figure charges

- Immediate publication on acceptance

- Inclusion in PubMed, CAS, Scopus and Google Scholar

- Research which is freely available for redistribution

Submit your manuscript at www.biomedcentral.com/submit 